\title{
Quasi-cubic $\alpha-\mathrm{Fe}_{2} \mathrm{O}_{3}$ Nanoparticles with Excellent Catalytic Performance
}

Yuanhui Zheng, Yao Cheng, Yuansheng Wang*, Feng Bao, Lihua Zhou, Xiaofeng Wei, Yingying Zhang, Qi Zheng

SI-1.

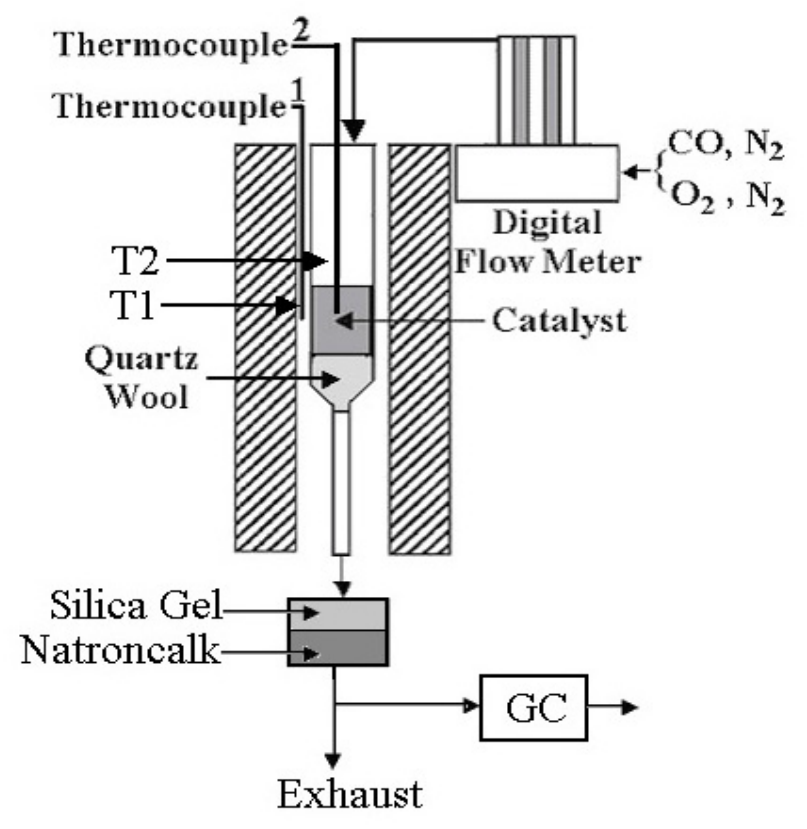

Figure S1. Schematic diagram of the flow tube reactor setup.

Note: Once the furnace's temperature (T1) reached the $\mathrm{T}_{100 \%}$, the temperature of catalyst bed (T2) increased instantly and was about $150^{\circ} \mathrm{C}$ higher than the furnace's temperature (T1), indicating the thermopositive reaction of $\mathrm{CO}$ catalytic oxide over $\alpha-\mathrm{Fe}_{2} \mathrm{O}_{3}$ catalyst. 
SI-2.
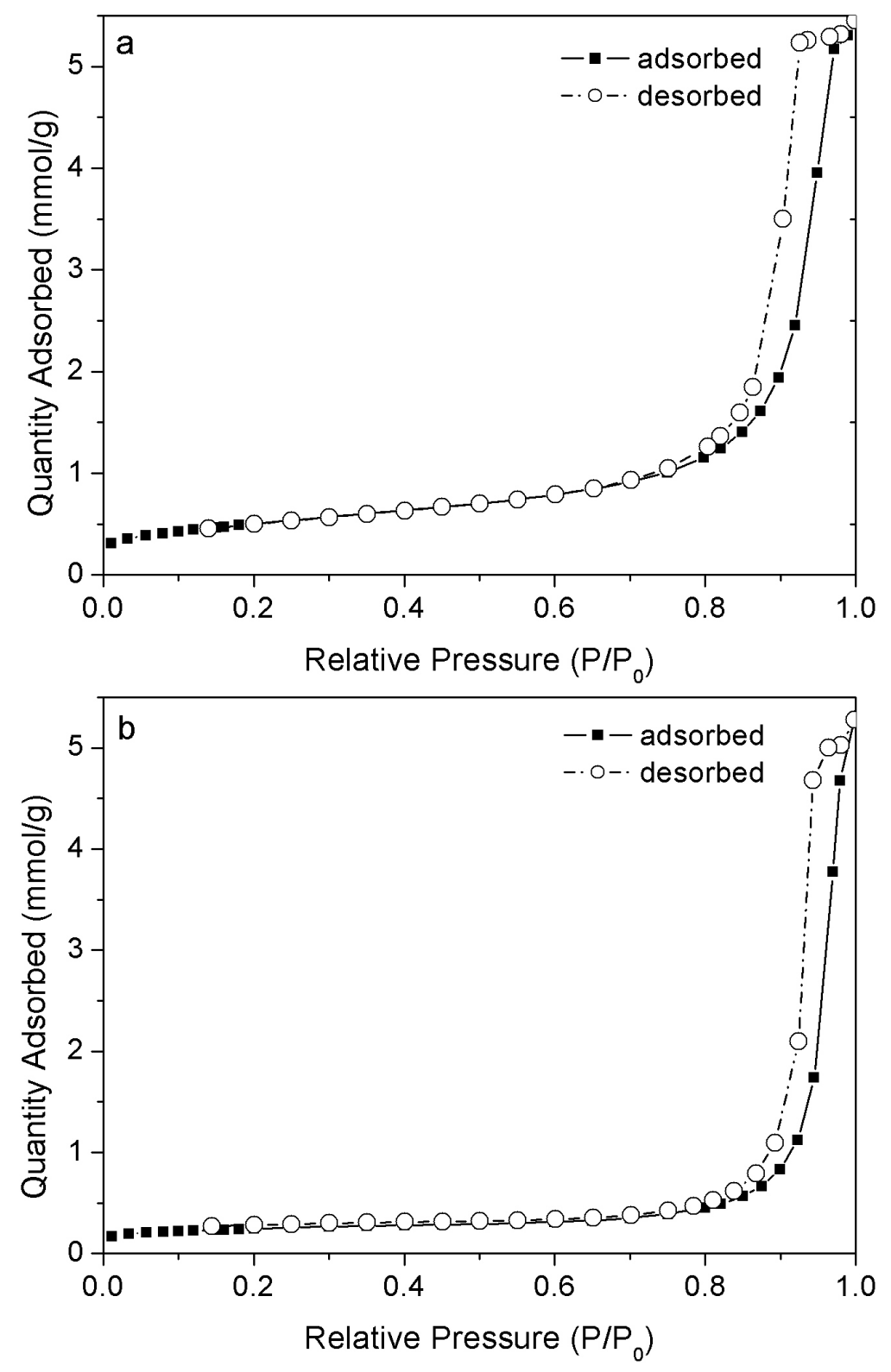

Figure S2. Nitrogen adsorption-desorption isotherm of (a) flower-like and (b) quasi-cubic $\alpha-\mathrm{Fe}_{2} \mathrm{O}_{3}$ nanoparticles.

Table 1. BET Surface Areas $\left(S_{\mathrm{BET}}\right)$, Total Pore Volume $\left(V_{\mathrm{p}}\right)$, and Pore Size $\left(D_{p}\right)$ of the products

\begin{tabular}{|c|c|c|c|}
\hline Samples & $S_{\mathrm{BET}}\left(\mathrm{m}^{2} / \mathrm{g}\right)$ & $V_{\mathrm{p}}\left(\mathrm{cm}^{3} / \mathrm{g}\right)$ & $\mathrm{D}_{\mathrm{p}}(\AA)$ \\
\hline flower-like & 39.9 & 0.179 & 179.7 \\
\hline quasi-cubic & 18.3 & 0.131 & 285.4 \\
\hline
\end{tabular}


SI-3.
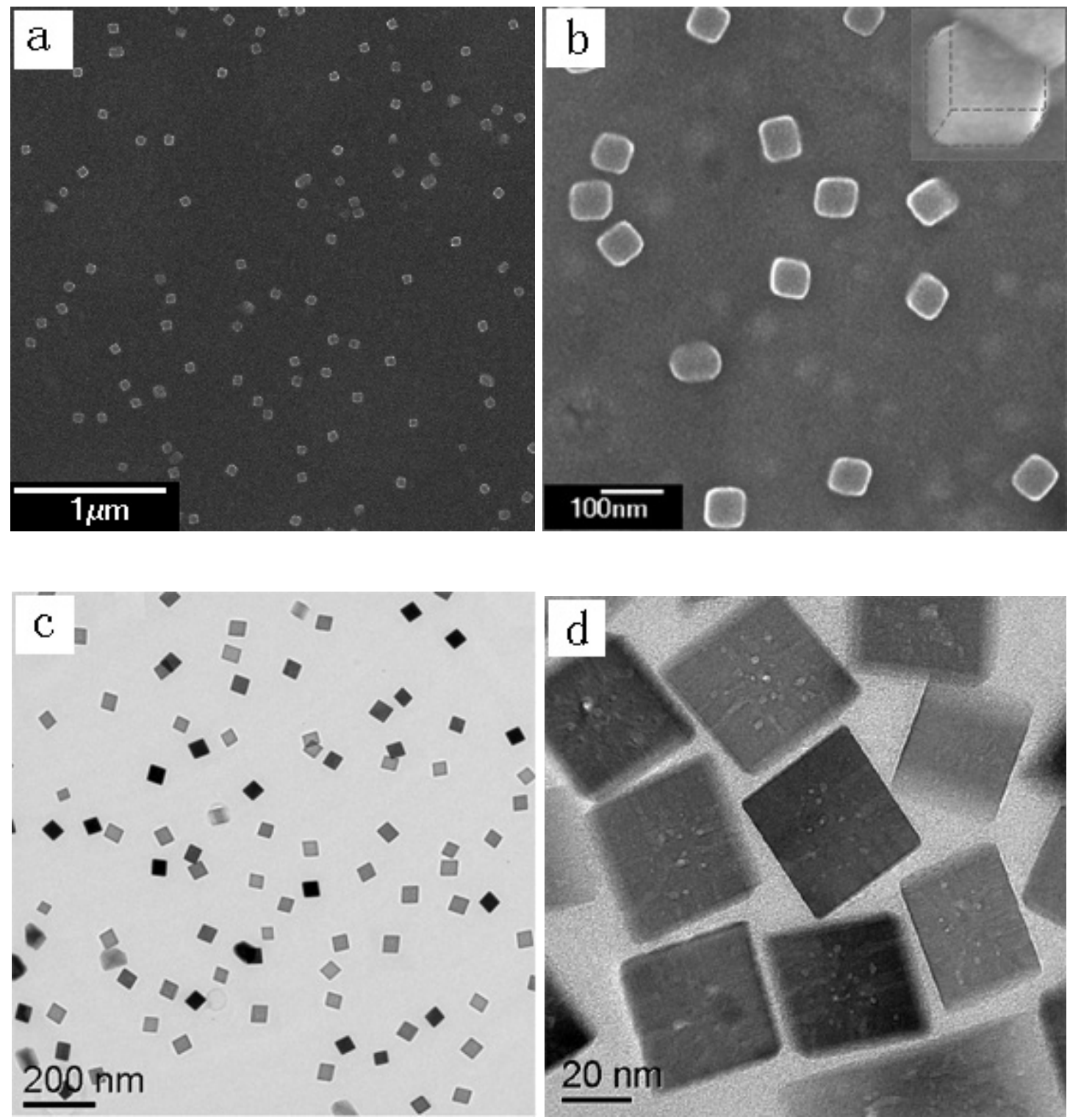

Figure S3. SEM images $(a, b)$ and TEM images $(c, d)$ of the quasi-cubic nanoparticles prepared at $180^{\circ} \mathrm{C}$ for $30 \mathrm{~h}$ with a molar ratio of PVP to iron salt of $2 \times 10^{-2}: 1$. 
SI-4.
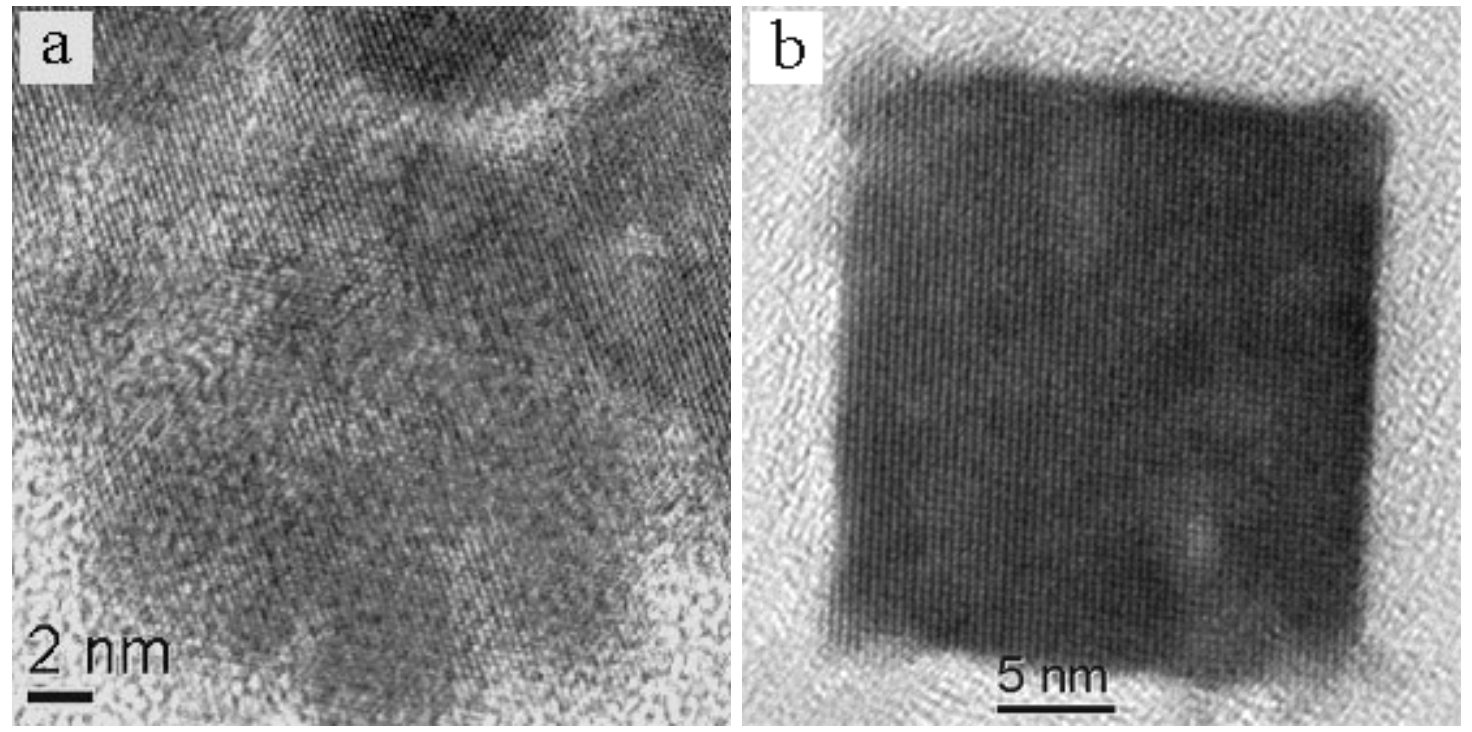

Figure S4. Magnified HRTEM images of (a) the squared region in the upper inset of Figure $3 b$, and (b) the quasi-cubic particle in the inset of Figure $3 c$.

SI-5.

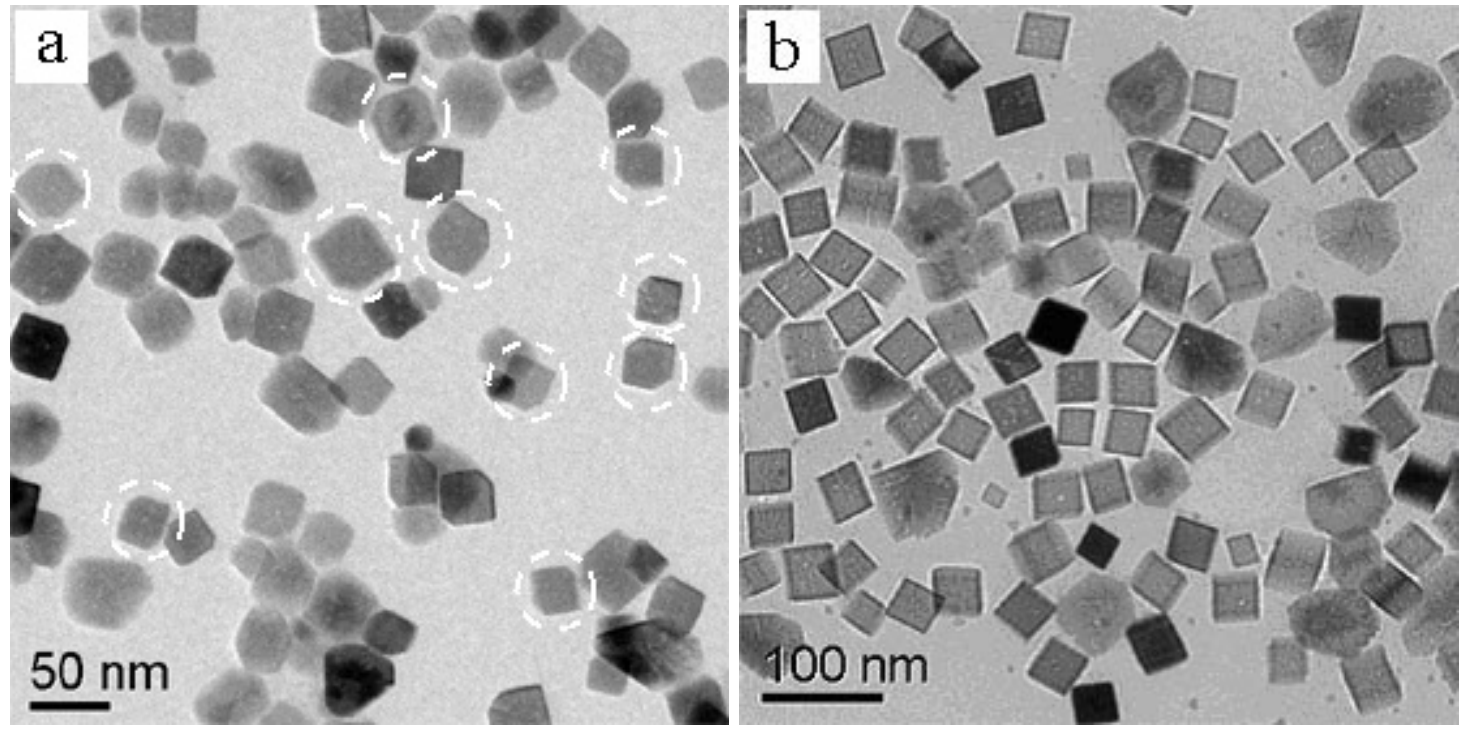


Figure S5. TEM images of the $\alpha-\mathrm{Fe}_{2} \mathrm{O}_{3}$ nanoparticles synthesized at $180^{\circ} \mathrm{C}$ for $30 \mathrm{~h}$ with molar ratios of PVP to iron salt: (a) $0: 1$, and (b) $1 \times 10^{-2}: 1$. The truncated quasi-cubic particles are highlighted by the circles.

SI-6.

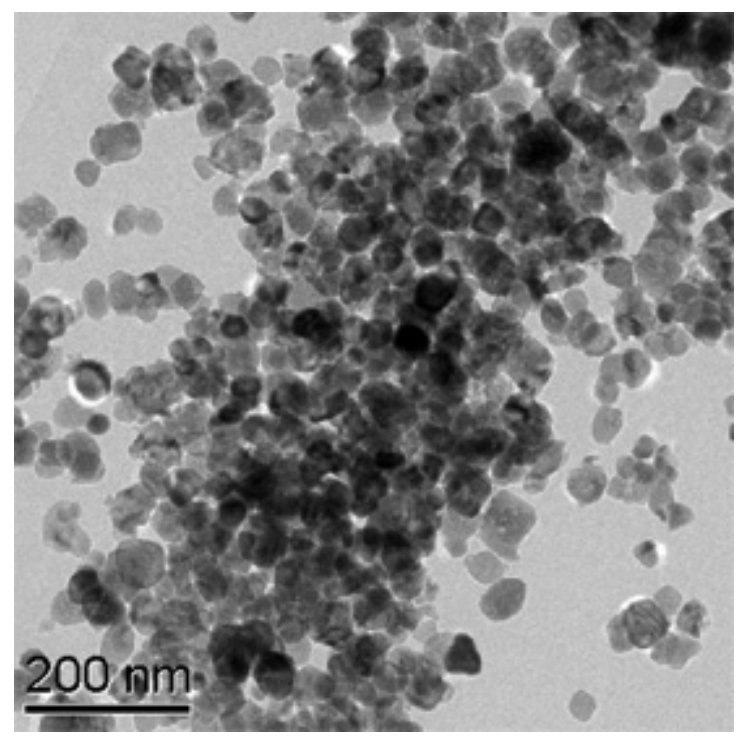

Figure S6. TEM image of the quasi-cubic $\alpha$-Fe $e_{2} \mathrm{O}_{3}$ nanoparticles after catalytic activity test for three runs. 